\title{
Chapter 6 \\ Seismic Analyses and Design of Foundation Soil Structure Interaction
}

\begin{abstract}
Alain Pecker
Abstract The topic of this paper is to illustrate on a real project one aspect of soil structure interaction for a piled foundation. Kinematic interaction is well recognized as being the cause of the development of significant internal forces in the piles under seismic loading. Another aspect of kinematic interaction which is often overlooked is the modification of the effective foundation input motion. As shown in the paper such an effect may however be of primary importance.
\end{abstract}

\subsection{Introduction}

Kinematic interaction is well recognized as being the cause of the development of significant internal forces in the piles under seismic loading. These internal forces are developed as the consequence of the ground displacement induced by the passage of the seismic waves. These displacements are imposed to the piles which may, or may not, follow the soil displacements depending on the bending stiffness of the piles relative to the soil shear stiffness (e.g. Kavvadas and Gazetas 1993). For flexible piles, the internal forces, i.e. pile bending moments and shear forces, can be computed by simply imposing the soil displacements to the pile; for stiff piles a soil structure analysis shall be conducted with proper modelling of the soil-pile interaction. Obviously, kinematic effects are more pronounced when the piles are stiff relative to the surrounding soil and when they cross consecutive layers of sharply different stiffnesses because the soil curvature is very large at such interfaces. This aspect of kinematic interaction is well understood and correctly accounted for in seismic design of piled foundations; for instance the European Seismic code (CEN 2004) requires that kinematic bending moments be computed whenever the two following conditions occur simultaneously:

\footnotetext{
A. Pecker $(\bowtie)$

Géodynamique et Structure, Bagneux, France

Ecole Nationale des Ponts ParisTech, Champs-sur-Marne, France

e-mail: alain.pecker@orange.fr
} 
- The ground profile has an average shear wave velocity smaller than $180 \mathrm{~m} / \mathrm{s}$ (ground type D) and contains consecutive layers of sharply differing stiffness; consecutive layers of sharply differing stiffness are defined as layers with a ratio for the shear moduli greater than 6 .

- The zone is of moderate or high seismicity, i.e. presents a ground surface acceleration larger than $0.1 \mathrm{~g}$, and the category of importance of the structure is higher than normal (importance category III or IV).

There is another aspect of kinematic interaction often overlooked, even in seismic building codes, which is the modification of the effective foundation input motion. For example the European Seismic code (CEN 2004) does not mention it, nor does the ASCE 41-13 standard (2014) which however dedicates several pages to the effect of kinematic interaction for shallow or embedded foundations.

This issue might be critical when substructuring is used and the global soilstructure-interaction problem is solved in several steps. However, when a global model including both the soil and the superstructure is contemplated, kinematic interaction is accounted for in the analysis, provided the global model correctly reflects the physical character of the problem. These aspects are illustrated below on a real bridge project.

\subsection{Soil Structure Interaction Modelling}

As opposed to spread footings, for which a single method of analysis to determine the forces transmitted by the foundation emerges in practice (based on a substructuring approach and the definition of the foundation stiffness matrix and damping), several modeling techniques are used to model piled foundations for seismic response studies; the most common methods are the simplified beam on Winkler foundation model and the coupled foundation stiffness matrix (substructuring). These two modeling techniques are illustrated in Fig. 6.1 for the global model and in Fig. 6.2 for the substructure model (Lam and Law 2000).

\subsubsection{Global SSI Model for Piled Foundations}

In the global model, piles are represented by beam elements supported by linear or nonlinear, depth-varying, Winkler springs. In the case of earthquake excitation, ground motion would impart different loading at each soil spring and these motions need to be calculated from a separate analysis (site response analysis). Kinematic interaction is therefore correctly accounted for. However, the main drawback of this modeling technique is the large number of degrees of freedom needed to formulate the complete system. 


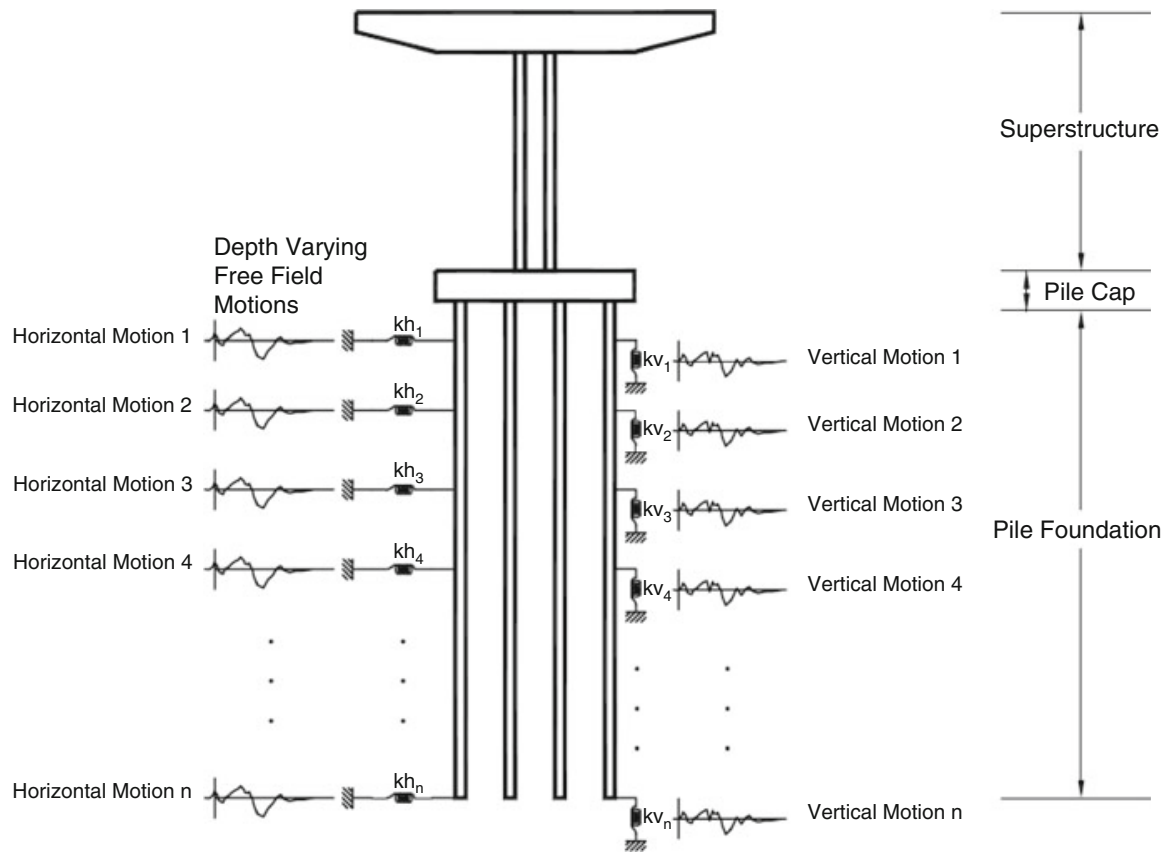

Fig. 6.1 Global pile-structure model

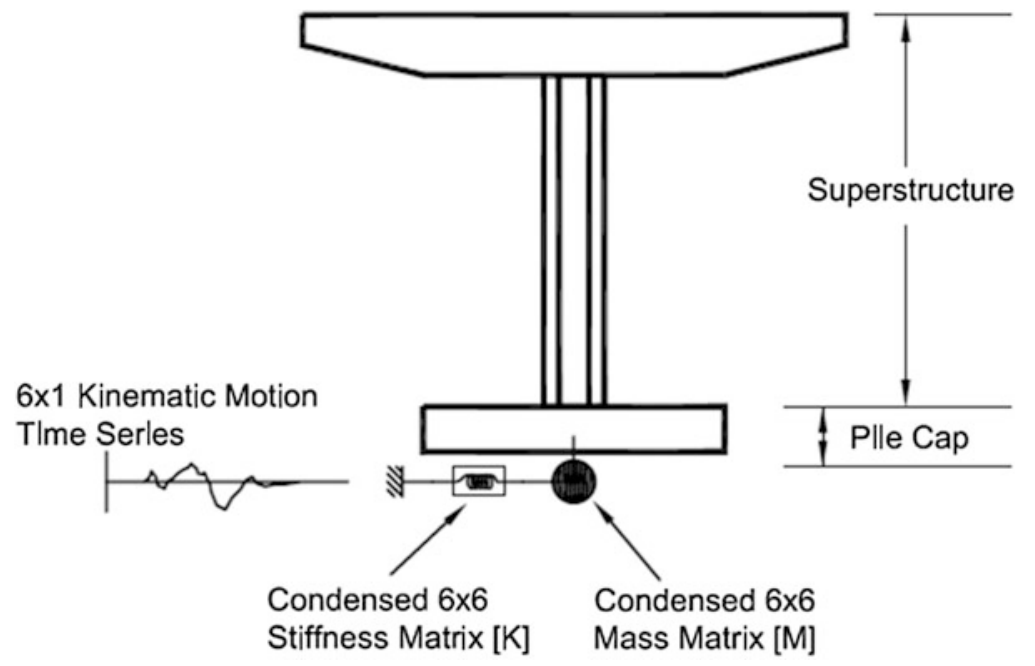

Fig. 6.2 Substructure model

The p-y relation, representing the nonlinear spring stiffness, is generally developed on the basis of a semi-empirical curve, which reflects the nonlinear resistance of the local soil surrounding the pile at specified depths. A number of p-y models 
have been proposed by different authors for different soil conditions. The two most commonly used p-y models are those proposed by Matlock et al. (1970) for soft clay and by Reese et al. (1974) for sand. These models are essentially semi-empirical and have been developed on the basis of a limited number of full-scale lateral load tests on piles of small diameters ranging from 0.30 to $0.40 \mathrm{~m}$. To extrapolate the $\mathrm{p}-\mathrm{y}$ criteria to conditions that are different from the one from which the $\mathrm{p}-\mathrm{y}$ models were developed requires some judgment and consideration. For instance in Slovenia, values of the spring stiffnesses are derived from the static values, increased by $30 \%$. Based on some field test results, there are indications that stiffness and ultimate lateral load carrying capacity of a large diameter drilled shaft are larger than the values estimated using the conventional p-y criteria. Pender (1993) suggests that the subgrade modulus used in $\mathrm{p}-\mathrm{y}$ formulation would increase linearly with pile diameter.

Studies have shown that Matlock and Reese p-y criteria give reasonable pile design solutions. However, the p-y criteria were originally conceived for design against storm wave loading conditions based on observation of monotonic static and cyclic pile load test data. Therefore, Matlock and Reese's static p-y curves can serve to represent the initial monotonic loading path for typical small diameter driven isolated piles. If a complete total system of a bridge is modeled for seismic response study, individual piles and p-y curves can be included in the analytical model.

However, for a large pile group, group effects become important. An example is given in Fig. 6.3 which presents the results of horizontal impedance calculations of the group of piles of half the foundation (22 piles) of one of the pylon of the Vasco da Gama bridge in Lisbon (Pecker 2003); the group efficiency, computed from elastodynamic theory, is of the order of $1 / 6$ at low frequencies and decreases with frequency due to the constructive interference of diffracted waves from adjacent piles. Typically, for large pile groups it is not uncommon to calculate group efficiency in the range $1 / 3$ to $1 / 6$.

Although group effect has been a popular research topic within the geotechnical community, currently there is no common consensus on the design approach to incorporate group effects. Full scale and model tests by a number of authors show that in general, the lateral capacity of a pile in a pile group is less than that of a single isolated pile due to so-called group efficiency. The reduction is more pronounced as the pile spacing is reduced. Other important factors that affect the efficiency and lateral stiffness of the pile are the type and strength of soil, number of piles, type and level of loading. In the past, analyses of group effects were based mostly on elastic halfspace theory due to the absence of costly full-scale pile experiments. In addition to group effect, gapping and potential cyclic degradation have been considered in the recent studies. It has been shown that a concept based on p-multiplier applied on the standard static loading p-y curves works reasonably well to account for pile group and cyclic degradation effects (Brown and Bollman 1996). The p-multiplier is a reduction factor that is applied to the p-term in the p-y curve for a single pile to simulate the behavior of piles in the group. 

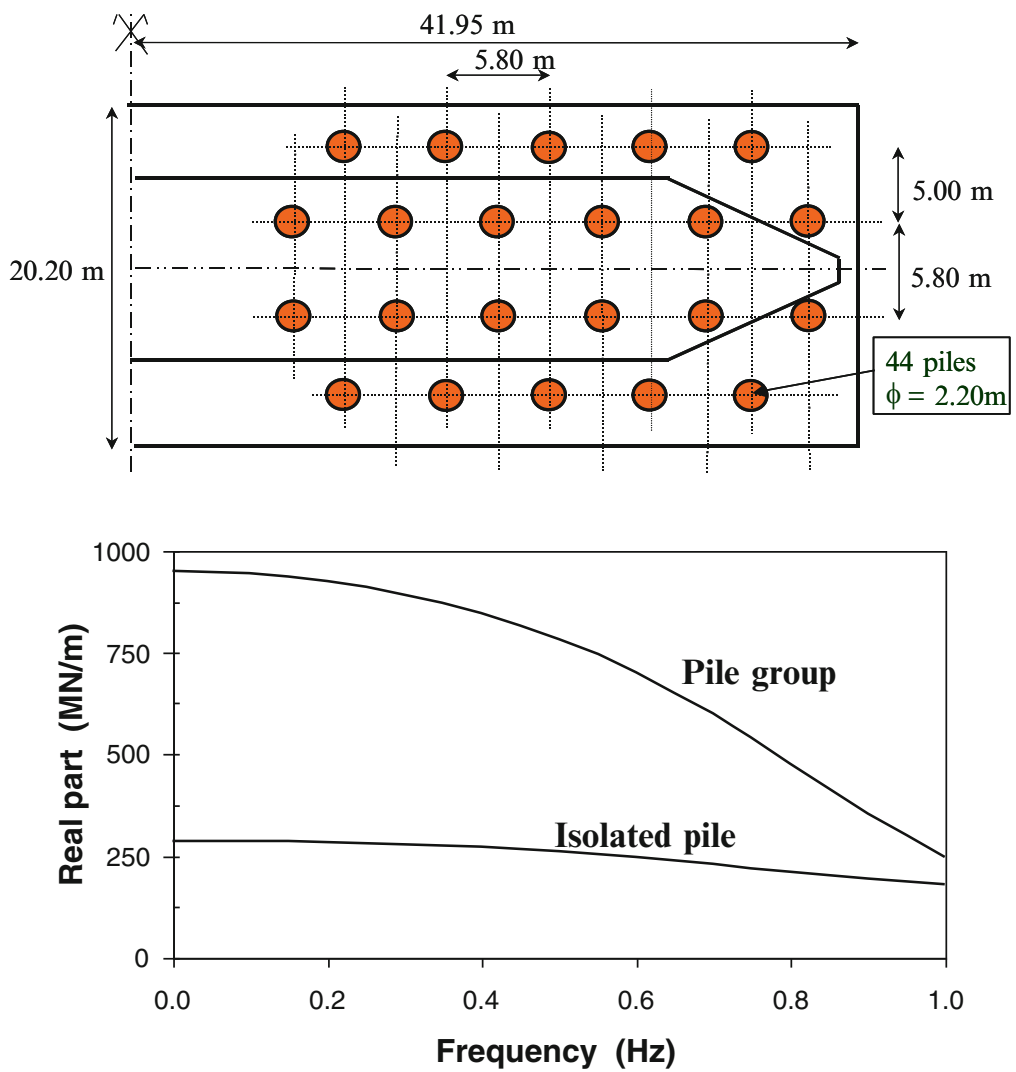

Fig. 6.3 Horizontal pile group impedance for the Vasco da Gama bridge (Pecker 2003)

\subsubsection{Substructure Model for Piled Foundations}

A direct (or global) interaction analysis in which both the soil and the structure are modelled with finite elements is very time demanding and not well suited for design, especially in 3D. The alternative approach employing a substructure system in which the foundation element is modeled by a condensed foundation stiffness matrix and mass matrix along with equivalent forcing function represented by the kinematic motion, may be more attractive; in addition, it more clearly separates the role of the geotechnical engineer and of the structural engineer. The substructuring approach is based on a linear superposition principle and therefore linear soil behavior is more appropriate. In that case, the condensed stiffness matrix may be obtained either from the beam on Winkler springs model or from continuum impedance solutions (Gazetas 1991). When nonlinear soil behavior is considered, the condensed stiffness matrix is generally evaluated by a pushover analysis of the pile group and linearization at the anticipated displacement amplitude of the pile head. 

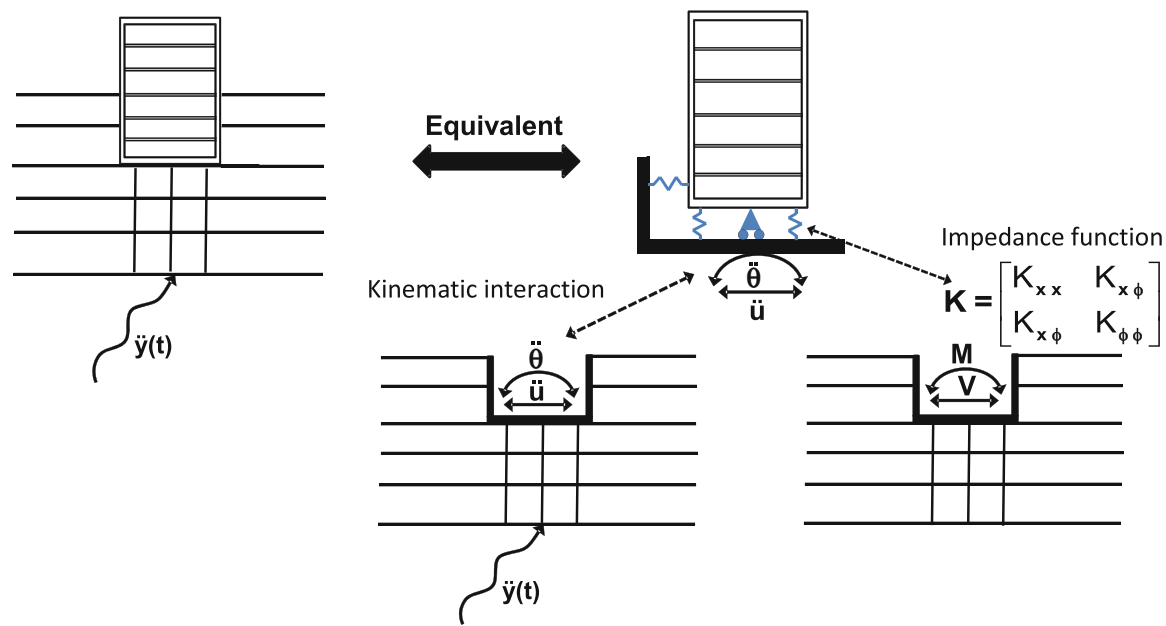

Fig. 6.4 Substructuring approach for soil structure interaction

Substructuring reduces the problem to more amenable stages and does not necessarily require that the whole solution be repeated again if modifications occur in the superstructure. It is of great mathematical convenience and rigor which stem, in linear systems, from the superposition theorem (Kausel et al. 1974). This theorem states that the seismic response of the complete system can be computed in two stages (Fig. 6.4)

- Determination of the kinematic interaction motion, involving the response to base acceleration of a system which differs from the actual system in that the mass of the superstructure is equal to zero;

- Calculation of the inertial interaction effects, referring to the response of the complete soil-structure system to forces associated with base accelerations equal to the accelerations arising from the kinematic interaction.

The second step is further divided into two subtasks:

- computation of the dynamic impedances at the foundation level; the dynamic impedance of a foundation represents the reaction forces acting under the foundation when it is directly loaded by harmonic forces;

- analysis of the dynamic response of the superstructure supported on the dynamic impedances and subjected to the kinematic motion, also called effective foundation input motion.

Although the substructure approach described above is rigorous for the treatment of linear SSI, its practical implementation is subject to several simplifications:

- full linear behavior of the system is assumed; it is well recognized that this assumption is a strong one since nonlinearities occur in the soil and at the soil pile interface. Soil nonlinearities can be partly accounted for, as recommended 
in Eurocode 8 - Part 5, by choosing for the calculation of the impedance matrix reduced soil properties, calculated from 1D site response analyses (Idriss and Sun 1992), that reflect the soil nonlinear behavior in the free field. This implicitly assumes that additional nonlinearities taking place at the soil pile interface, along the pile shaft, do not contribute significantly to the overall seismic response.

- kinematic interaction is usually not considered. Very often flexural piles are flexible with respect to the surrounding soil and the soil displacement is not altered by the presence of the pile group. In that case, provided the foundation embedment can be neglected, step 1 is straightforward: the kinematic interaction motion, or foundation effective input motion, is simply the freefield motion. No additional burden is imposed to the analyst since the freefield motion is a given input data.

\subsection{Kinematic Interaction Motion}

In the remaining of the paper we will focus on the first step of the substructure analysis described above with illustration of two foundations responses of the same bridge.

Foundation 1 is composed of 18 concrete piles, $1,800 \mathrm{~mm}$ in diameter, $20 \mathrm{~m}$ long, penetrating a $2.50 \mathrm{~m}$ thick layer of a residual soil with a shear wave velocity $300 \mathrm{~m} / \mathrm{s}$, overlying a $10 \mathrm{~m}$ thick weathered layer of the rock formation with a shear wave velocity of $580 \mathrm{~m} / \mathrm{s}$; the rock formation is found at $12.50 \mathrm{~m}$ below the ground surface. Site response analyses were carried out with the software SHAKE (linear equivalent viscoelastic model) and for seven time histories spectrally matched to the design spectrum; these time histories were input at an outcrop of the rock formation. The foundation response was modeled with the software SASSI-2010; (Ostadan et al. 2010) the model includes the 18 piles, a massless pile cap and the soil layers; the strain compatible properties retrieved from the SHAKE analyses are used for each soil layer and the input motion is represented by the seven ground surface time histories computed in the SHAKE analyses. Figure 6.5 compares the freefield ground surface spectrum to the foundation response spectra calculated at the same elevation. Note that because of the asymmetric pile layout the motion in the X-direction is different from the motion in the Y-direction. As expected since the soil profile is stiffer than the piles in flexure, both the freefield motion and the foundation motions are very close to each other. For that configuration, using the freefield motion for the effective foundation input motion would not be a source of error.

Foundation 2 of the same bridge is composed of 35 large diameter concrete piles $(2.5 \mathrm{~m}), 49 \mathrm{~m}$ long, crossing a very soft mud layer, $11 \mathrm{~m}$ thick, with a shear wave velocity of the order of $100 \mathrm{~m} / \mathrm{s}$; the piles go through a residual soil $\left(V_{\mathrm{S}}=250-400\right.$ $\mathrm{m} / \mathrm{s}$ ) and reach the competent rock formation at $25 \mathrm{~m}$ depth (Fig. 6.6). Freefield and foundation response spectra are compared in Fig. 6.7 The free-field ground response spectrum determined from a site specific response analysis has a smooth shape; the kinematic interaction motion, i.e. the motion of the piled foundation, 


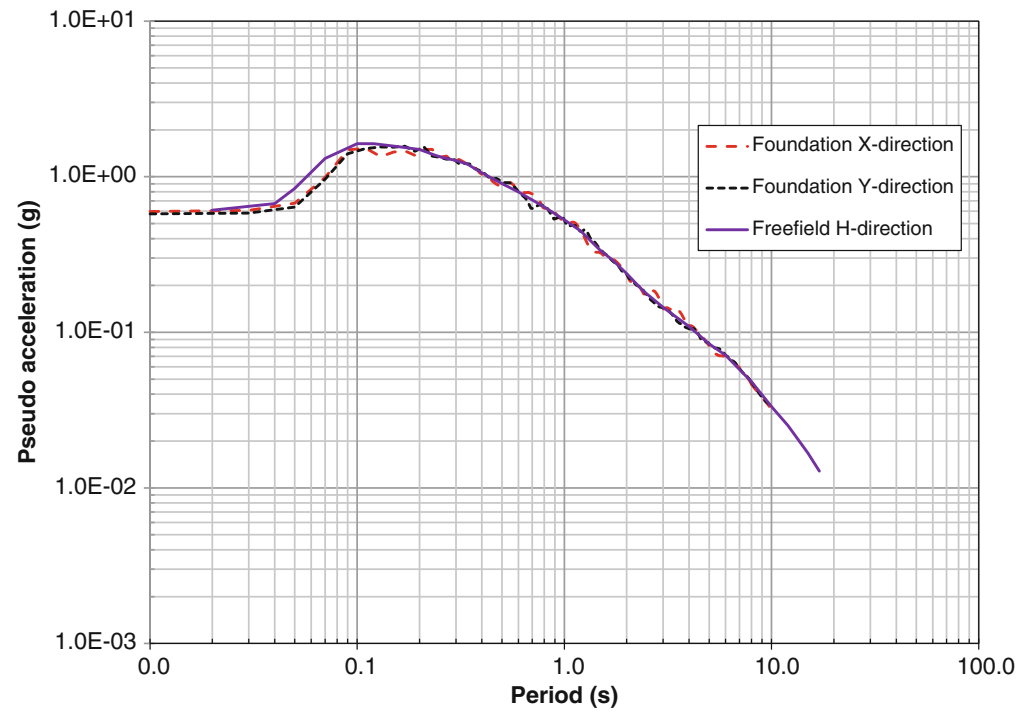

Fig. 6.5 Kinematic interaction motion for "flexible" piled foundation 1

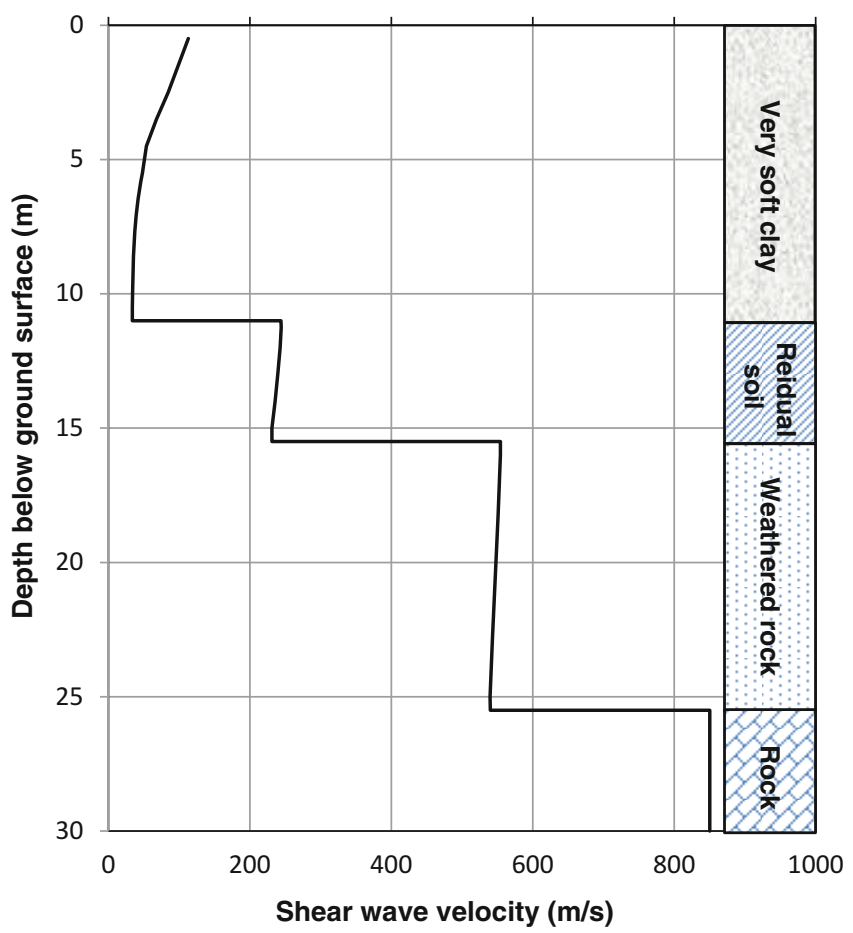

Fig. 6.6 Soil profile at location of foundation 2 


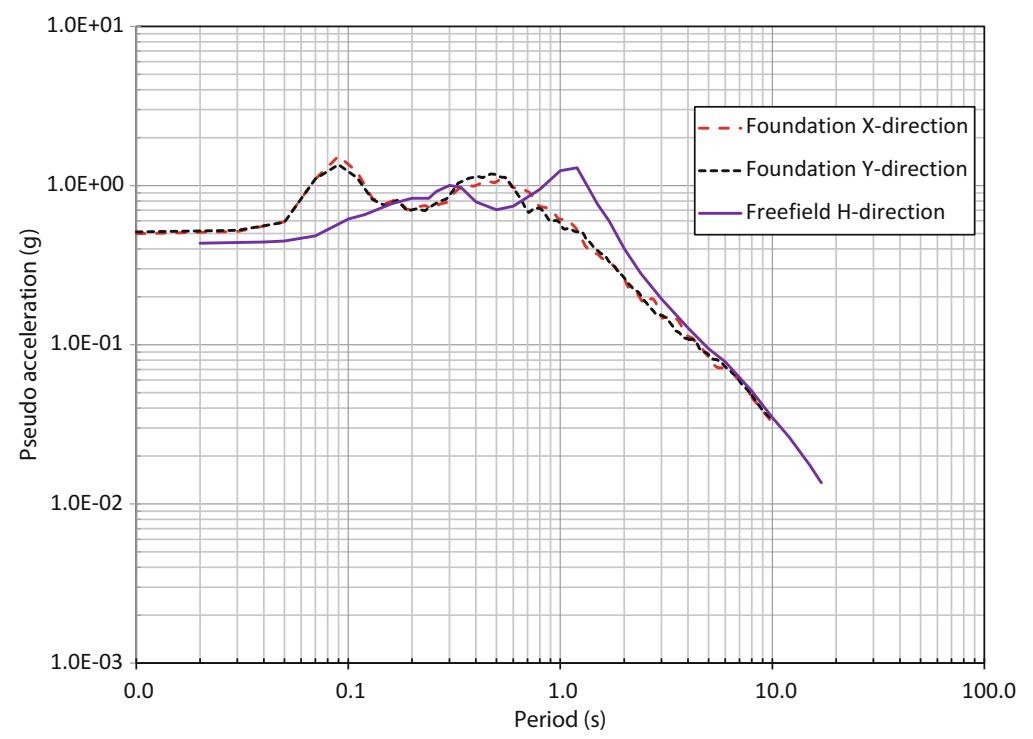

Fig. 6.7 Kinematic interaction motion for "stiff" piled foundation 1

exhibits a marked peak at $0.5 \mathrm{~s}$ and a significant deamplification with respect to the free-field motion between 0.8 and $3.0 \mathrm{~s}$. This phenomenon is due to the inability of the piled foundation to follow the ground motion because of the piles stiffnesses.

Obviously, in that case, using the freefield motion for the foundation input motion would be strongly misleading and may produce an unconservative design.

These two examples, drawn from a real project clearly illustrate the need for a careful examination of the relative foundation-soil profile stiffness before deciding whether or not there is a chance that the freefield motion be modified by the foundation. When faced to that latter situation, it is mandatory to correctly evaluate the effective foundation input motion to obtain meaningful results.

\subsection{Conclusions}

Experience gained from several projects involving piled foundation in a seismic environment shows that the most amenable and versatile approach to soil structure interaction is the substructuring technique. It presents several advantages like a correct treatment of the pile group effect, which is not the case with a global model where the piles are modelled as beams on Winkler foundations, the need for calculating the foundation input motions and foundation impedances only once as long as the foundation is not modified, the reduced size of the structural model, especially for extended structures like bridges, etc... . The main drawback of this approach lies in its restriction to linear, or moderately nonlinear, systems. Since it is 
attractive, the method is often used with approximations in its implementation and the designer must be fully aware of those shortcuts. In this paper, one such approximation, which consists in taking the freefield motion for the effective foundation input motion, has been illustrated on a real project. It has been shown that significant differences may take place between both motions when the piled foundation cannot be considered flexible with respect to the soil profile. If this situation is faced, rigorous treatment of soil-structure interaction requires that the effective foundation input motion be calculated, an additional step in the design.

Open Access This chapter is distributed under the terms of the Creative Commons Attribution Noncommercial License, which permits any noncommercial use, distribution, and reproduction in any medium, provided the original author(s) and source are credited.

\section{References}

ASCE/SEI 41-13 (2014) Chapter 8: Foundations and geologic site hazards. In: Seismic evaluation and retrofit of existing buildings, vol 52. American Society of Civil Engineers, Reston, pp 1-8

Brown DA, Bollman HT (1996) Lateral load behavior of pile group in sand. J Geotech Eng ASCE 114(11):1261-1276

CEN (2004) European Standard EN 1998-5: 2004 Eurocode 8: Design of structures for earthquake resistance. Part 5: Foundations, retaining structures, geotechnical aspects. Comité Europeen de Normalisation, Brussels

Gazetas G (1991) Foundation vibrations. In: Fang HY (ed) Foundation engineering handbook, 2nd edn. Van Nostrand Rheinhold, New York

Idriss IM, Sun JI (1992) SHAKE 91: a computer program for conducting equivalent linear seismic response analyses of horizontally layered soil deposits. Program modified based on the original SHAKE program published in December 1972 by Schnabel, Lysmer and Seed, Center of Geotechnical Modeling, Department of Civil Engineering, University of California, Davis

Kausel E, Roesset JM (1974) Soil structure interaction for nuclear containment structures. Proceedings ASCE, power division specialty conference, Boulder

Kavvadas M, Gazetas G (1993) Kinematic seismic response and bending of free head piles in layered soils. Geotechnique 43(2):207-222

Lam PI, Law H (2000) Soil structure interaction of bridges for seismic analysis. Technical report MCEER-00-008

Matlock H (1970) Correlation for design of laterally loaded piles in soft clay. 2nd Annual Offshore Technology Conference. Paper No 1204

Ostadan F, Nan D (2012) SASSI 2010 - a system for analysis of soil-structure interaction. Geotechnical Engineering Division, Civil Engineering Department, University of California, Berkeley

Pecker A (2003) Aseismic foundation design process - lessons learned from two major projects: the Vasco da Gama and the Rion-Antirion bridges. Proceedings 5th ACI international conference on seismic bridge design and retrofit for earthquake resistance, La Jolla

Pender MJ (1993) Aseismic pile foundation design and analysis. Bull N Z Soc Earthq Eng 26 (1):49-160

Reese L, Cox W, Koop R (1974) Analysis of laterally load piles in sand. 6th Annual Offshore Technology Conference. Paper No. 2080 